\title{
PENERAPAN METODE MODULUS FUNCTION (MF) UNTUK PENYISIPAN PESAN PADA CITRA DIGITAL
}

\author{
Raimah Handayani Harahap ${ }^{1}$, Nelly Astuti Hasibuan², Imam Saputra ${ }^{3}$ \\ Program Studi, Teknik Informatika STMIK Budi Darma, Medan Indonesia \\ Jalan Sisingamangaraja N0.388, Medan Indonesia
}

\begin{abstract}
Abstrak
Steganografi adalah ilmu dan seni menyembunyikan (embedded) informasi dengan cara menyisipkan pesan rahasia di dalam pesan lain. Steganografi di bidang teknologi informasi sangat berkembang, yaitu untuk perangkat-perangkat digital. Informasi atau pesan yang dapat disembunyikan beragam, begitu pula dengan pesan yang menjadi objek tersisip. Variasi pesan yang biasa menjadi subjek dan objek penyisipan adalah pesan teks, pesan gambar, pesan audio, dan pesan video. Metode steganografi yang digunakan yaitu metode Modulus Function (MF). Metode ini dapat menyisipkan pesan lebih banyak pada pixel yang memiliki nilai kekontrasan tinggi. Penelitian yang dilakukan yaitu menerapkan metode Modulus Function (MF) untuk penyisipan pesan kedalam file gambar. Berdasarkan hasil pengujin didapat kesimpulan bahwa dengan menggunakan metode Modulus Function (MF), kapasitas citra untuk menyisipkan pesan, lebih kecil dari ukuran citranya, waktu proses pada metode ini cukup cepat, kualitas citra setelah disisipi pesan mempunyai kualitas yang baik, namun metode ini juga masih mempunyai kekurangan, karena tidak tahan terhadap manipulasi dan pada beberapa citra masih terdeteksi oleh aplikasi matlab.
\end{abstract}

Kata Kunci : Steganografi, Penerapan, Modulus Function(MF), file Gambar.

\begin{abstract}
Steganography is the science and art of hiding (embedded) information by inserting secret messages in other messages. Steganography in the field of information technology is highly developed, namely for digital devices. Information or messages that can be hidden varies, as can messages that are embedded objects. Variations of messages that are normally subject to insertion objects are text messages, picture messages, audio messages, and video messages. The steganography method used is the Modulus Function (MF) method. This method can insert more messages into pixels that have high contrast values. The research conducted is applying the Modulus Function (MF) method for inserting messages into image files. Based on the test results, it can be concluded that by using the Modulus Function (MF) method, the capacity of the image to insert a message is smaller than the image size, the processing time in this method is quite fast, the image quality after inserting a message has good quality, but this method is also still good. has disadvantages, because it is not resistant to manipulation and in some images are still detected by the matlab application.
\end{abstract}

Keywords: Steganography, Implementation, Modulus Function (MF), Image file.

\section{PENDAHULUAN}

Munculnya teknologi internet dan multimedia telah mendorong berbagai macam usaha untuk melindungi, mengamankan dan menyembunyikan data pada file digital dari pihak-pihak yang tidak mempunyai otoritas mengakses file-file tersebut. Salah satu usaha untuk mengamankan data diantaranya dengan menggunakan kriptografi. Berbagai macam algoritma kriptografi dapat diimplementasikan untuk mewujudkan sistem keamanan data. Selain kriptografi juga terdapat steganography sebagai alternatif untuk mengamankan data.

Dengan tersedianya jaringan internet, memungkinkan untuk melakukan proses pertukaran data dan informasi. Dalam tukar menukar informasi, aspek keamanan memegang peranan penting, terutama jika informasi tersebut bersifat rahasia. Untuk menjaga kerahasiaan informasi dapat digunakan teknik steganography. Informasi yang akan dikirim disembunyikan dalam file digital (teks, image, audio, video). Kemudian data digital tersebut dikirim seperti data biasa, sehingga pihak ketiga tidak curiga bahwa didalamnya terdapat informasi rahasia. Informasi yang disembunyikan dalam data digital tersebut dapat diekstrak kembali oleh penerima pesan. Informasi tersebut juga harus sama dengan informasi sebelum disisipkan dalam data digital, meskipun data digital tersebut telah mengalami proses manipulasi, seperti pengeditan, pemotongan atau kompresi.

Steganografi merupakan seni dalam menyembunyikan informasi sedemikian rupa dalam suatu wadah sehingga pesan yang disembunyikan tidak diketahui atau tidak terdeteksi. Keutamaan steganografi adalah menyembunyikan pesan rahasia kedalam media penampung. Secara teknis teknik steganografi memanfaatkan kelemahan dari kesadaran manusia. Indra manusia yang terbatas tidak terlatih untuk mencari file yang tersembunyi didalam suatu wadah selama tidak mengubah bentuk dari wadah penampung tersebut.

Metode Modulus Function (MF)merupakan teknik penyisipan pesan yang dilakukan melalu modifikasi nilai sisa hasil bagi (remainder) metode ini menggunakan kuantisasi selisih nilai keabuan untuk menentukan jumlah bit yang akan disisipkan pada selisih nilai tertentu salah satu nilai yang di gunakan adalah [8 8163264 128][1].

Dalam pemilihan jenis media yang digunakan sembarang. Kualitas citra dapat dilihat pada citra sebelum dan sesudah disisipi oleh pesan, selain itu terdapat tiga persyaratan untuk steganografi yang efektif yakni kapasitas (capasity), tingkat visibilitas (impereceptibility), dan kekokohan (robustnees). Kelebihan pada metode Modulus Function ini adalah mampu mengurangi perubahan nilai koefisien (coefficient adjustment) sehingga mampu 
meningkatkan citra. Modulus function juga bekerja pada rentan integer sehingga sesuai dengan IHWT yang bekerja pada rentan integer[2].

\section{TEORITIS}

\subsection{Pesan}

Pesan dalam bahasa Prancis ditulis message (baca: mesaz), berasal dari bahasa latin "missus" artinya mengirim. Kata message digunakan sejak akhir abad ke XI oleh para penutur atau partisipan komunikasi untuk mengatakan "sesuatu yang kita kirimkan" (ce que l'on transmet, baca: Dictionaire de Petit Robert).

Dari uraian diatas dapat disimpulkan bahwa pesan adalah representasi gagasan komunikator yang dipertukarkan dalam wujud tanda-tanda tertentu (utamanya yang bersifat fisik), yang isinya mengandung maksud tertentu[6]. Pesan biasanya dengan sengaja disalurkan oleh komunikator kepada komunikan untuk mendapatkan hasil tertentu, yang biasanya telah ditetapkan.

Pada umumnya citra digital berbentuk empat persegi panjang denagan lebar dan panjang tertentu. Ukuran citra biasanya diukur dalam jumlah titik atau piksel, dimana setiap piksel mempunyai koordinat menurut letaknya didalam citra digital. Koordinat ini biasanya dinyatakan dalam bilangan integer yang besarnya dari 0 samapi dengan 1tergantung dari sistem yang digunakan. Setiap piksel berisi nilai yang mewakili informasi apa yang ada didalam piksel. Citra (image) juga dapat didefenisikan sebagai fungsi dua dimensi $f(x, y)$ dimana $x$ dan $y$ adalah koordinat spasial dan amplitudo pada setiap pasang $(x, y)$ disebut intensitas (gray level) citra pada titik tersebut. Jika $x$ dan yberhingga (finite) dan diskrit (tidak kontinyu) maka disebut citra digital. Citra digital terdiri dari sejumlah elemen berhingga yang masing-masing mempunyai lokasi dan nilai, Elemen-elemen $x$ dan ydisebut elemen citra atau pels atau piksel.

\subsection{Modulus Function}

Metode Modulus Function (MF) ini merupakan pengembangan dari metode PVD. Proses penyisipan pesan dilakukan melalui modifikasi nilai sisa hasil bagi (remainder)dari piksel bertetangga. Sama seperti metode PVD, metode ini menggunakan kuantitasi selisih nilai keabuan untuk menentukan jumlah bit yang akan disisipkan pada selisih nilai tertentu[11]. Salah satu rentang nilai yang digunakan adalah [ $\left.\begin{array}{lllllll}8 & 8 & 16 & 32 & 64 & 128\end{array}\right]$. Langkah-langkah penyisipan pesan .

Tabel 1. Rentang Nilai

\begin{tabular}{llll}
\hline Kuantisasi Ke-k & Batas Bawah - Batas Atas $\mathrm{L}_{\mathrm{k}}-\mathrm{u}_{\mathrm{k}}$ & Rentang Nilai & Jumlah Bit N \\
\hline 1 & $0-7$ & 8 & 3 \\
2 & $8-15$ & 8 & 3 \\
3 & $16-31$ & 16 & 4 \\
4 & $32-63$ & 32 & 5 \\
5 & $64-127$ & 64 & 6 \\
6 & $128-255$ & 128 & 7 \\
\hline
\end{tabular}

1. Ubah pesan menjadi bilangan biner 8 bit.

2. Hitung selisih 2 piksel bertetangga $\left(\boldsymbol{g}_{\mathrm{i}}, \boldsymbol{g}_{\mathrm{i}+\mathbf{1}}\right) \mathrm{d}_{\mathrm{i}}=\left|g_{\mathrm{i}+1}-\boldsymbol{g}_{\mathrm{i}}\right|$

3. Tentukan batas bawah ( $\left.\mathbf{I}_{\mathbf{k}}\right)$ dan jumlah bit $\mathbf{n}$, dengan cara : $\mathrm{l}_{\mathrm{k}} \leq \mathrm{d}_{\mathrm{i}}<\mathrm{l}_{\mathrm{k}+1}$

4. Ambil pesan sebanyak $\mathbf{n}$ bit, kemudian ubah menjadi desimal (b)

5. Hitunglah nilai sisal hasil bagi (remainder) $\mathrm{r}=\left(\mathrm{g}_{\mathrm{i}}+\mathrm{g}_{\mathrm{i}+1}\right) \bmod \mathbf{2}^{\mathrm{n}}$

6. Hitung : $\mathrm{m}|\mathrm{r}-\mathrm{b}|$ dan $\mathrm{m}^{\prime}=\left|2^{\mathrm{n}}-\mathrm{m}\right|$

7. Tentukan nilai piksel baru $\boldsymbol{g}_{\mathbf{i}}$,, $\boldsymbol{g}_{\boldsymbol{i}+\mathbf{1}}$, dengan cara berikut:

a. Jika $\mathrm{r}>\mathrm{b}$ dan $\mathrm{m} \leq 2^{n} / 2$ dan $g_{1}-g_{i+1^{\prime}}$

b. maka

$\left.\left(g_{\mathrm{i}}{ }^{\prime}, g_{i+1}\right)^{\prime}\right)=\left(g_{i}-\left[\frac{m}{2}\right], g_{i+1}-\left[\frac{m}{2}\right]\right)$

c. Jika $\mathrm{r}>\mathrm{b}$ dan $\mathrm{m} \leq 2^{n} / 2$ dan $g_{1}-g_{i+1^{\prime}}$ maka

$\left(g_{\mathrm{i}}{ }^{\prime}, g_{i+1}\right)^{\prime}=\left(g_{i}-\left[\frac{m}{2}\right], g_{i+1}-\left[\frac{m}{2}\right]\right)$

d. Jika $\mathrm{r}>\mathrm{b}$ dan $\mathrm{m} \leq 2^{n} / 2$ dan $g_{1}-g_{i+1^{\prime}}$ maka

$\left(g_{\mathrm{i}}{ }^{\prime}, g_{i+1}{ }^{\prime}\right)=\left(g_{i}-\left[\frac{m}{2}\right], g_{i+1}+\left[\frac{m}{2}\right]\right)$

e. Jika $\mathrm{r}>\mathrm{b}$ dan $\mathrm{m} \leq 2^{n} / 2$ dan $g_{1}-g_{i+1^{\prime}}$ maka $\left(g_{\mathrm{i}}{ }^{\prime}, g_{i+1}\right)^{\prime}=\left(g_{i}-\left[\frac{m}{2}\right], g_{i+1}+\left[\frac{m}{2}\right]\right)$

f. Jika $\mathrm{r}>\mathrm{b}$ dan $\mathrm{m} \leq 2^{n} / 2$ dan $g_{1}-g_{i+1^{\prime}}$ maka $\left(g_{\mathrm{i}}{ }^{\prime}, g_{i+1}^{\prime}\right)=\left(g_{i}-\left[\frac{m}{2}\right], g_{i+1}+\left[\frac{m}{2}\right]\right)$

g. Jika $\mathrm{r}>\mathrm{b}$ dan $\mathrm{m} \leq 2^{n} / 2$ dan $g_{1}-g_{i+1^{\prime}}$ maka 

$\left(g_{\mathrm{i}}{ }^{\prime}, g_{i+1}\right)^{\prime}=\left(g_{i}-\left[\frac{m}{2}\right], g_{i+1}+\left[\frac{m}{2}\right]\right)$
h. Jika $\mathrm{r}>$ b dan $\mathrm{m} \leq 2^{n} / 2$ dan $g_{1}-g_{i+1^{\prime}}$ maka $\left(g_{\mathrm{i}}, g_{i+1}^{\prime}\right)=\left(g_{i}-\left[\frac{m}{2}\right], g_{i+1}-\left[\frac{m}{2}\right]\right)$
i. Jika $\mathrm{r}>$ b dan $\mathrm{m} \leq 2^{n} / 2$ dan $g_{1}-g_{i+1^{\prime}}$ maka $\left(g_{\mathrm{i}}, g_{i+1}^{\prime}\right)=\left(g_{i}-\left[\frac{m}{2}\right], g_{i+1}-\left[\frac{m}{2}\right]\right)$

Sebuah pesan "154akan di sisipkan ke sebuah citra grayscale" 8 bit berukuran $4 \times 4$ piksel menggunakan metode MF. Langkah-langkah penyisipan pesan

Iterasi ke-1:

1. Pesan " 154 " di ubah jadi biner 8 bit.

Pesan = "1 $0001110010 "$

2. $\mathrm{d}_{\mathrm{i}}=|200-105|=95$

3. $64 \leq \mathrm{d}_{\mathrm{i}}<127 \mathrm{n}=6, \mathrm{l}_{\mathrm{k}}=\mathbf{6 4}, 2^{\mathrm{n}}=64$

4. $\mathbf{B}=1000110=38$, sisa pesan $=$ " 10 "

5. $\mathrm{R}=\left(\mathrm{g}_{\mathrm{i}}+\mathrm{g}_{\mathrm{i}+1}\right) \bmod 2^{\mathrm{n}}=(200+105) \bmod 64=305 \bmod 64=49$

6. $\mathrm{M}=|\mathrm{r}-\mathrm{b}|=|49-38|=11$ dan $\mathrm{m}^{\prime}=\left|2^{\mathrm{n}} \mathrm{-m}\right|=|64-11|=53$.

7. $\mathbf{r}=49, \mathbf{b}=38, \mathrm{~m}=11, \mathrm{l}_{\mathrm{k}} / 2=32$ dan $g_{\mathrm{i}}=105, g_{\mathrm{i}+1}=200$ yang memenuhi syarat adalah poin (b) jika, $r>b$ dan $m$ $\leq 2^{\mathrm{n}} / 2$ dan $\boldsymbol{g}_{\mathrm{i}}\left\langle\boldsymbol{g}_{\mathrm{i}+1}, \operatorname{maka}\left(\boldsymbol{g}_{\mathrm{i}} \boldsymbol{g}_{\mathrm{i}+1}\right)=\left(\boldsymbol{g}_{\mathrm{i}}-\left[\frac{\boldsymbol{m}}{2}\right], \boldsymbol{g}_{\boldsymbol{i}+\mathbf{1}}-\left[\frac{\boldsymbol{m}}{2}\right]\right)\right.$
$\left(g \mathrm{i}^{\prime} \boldsymbol{g i}+1\right)=\left(105-\left[\frac{11}{2}\right], 200-\left[\frac{11}{2}\right]\right)=(105-5,200-6)=(100,194)$

Iterasi ke-2:

1. Pesan $=$ " 10 "

2. $\mathrm{d}_{\mathrm{i}}=|28-57|=29$

3. $16 \leq \mathrm{d},<31 \mathbf{n}=4, \mathbf{l}_{\mathbf{k}}=\mathbf{1 6}, 2^{\mathrm{n}}=16$

4. $\mathbf{b}=10$, tambahkan 2 bit agar $=4$, jadi $b=1000=8$ sisa pesan $=$ habis

5. $\mathrm{r}=\left(g_{\mathrm{i}+} g_{\mathrm{i}+1}\right) \bmod 2^{\mathrm{n}}=(57-28) \bmod 16=85 \bmod 16=5$

6. $\mathrm{m}=|\mathrm{r}-\mathrm{b}|=|5-8|=3$ dan $\mathrm{m}^{\prime}=\left|2^{\mathrm{n}}-\mathrm{m}\right|=|16-3|=13$

7. $\mathbf{r}=5, \mathbf{b}=8, \mathbf{m}=3,2^{\mathrm{n}} / 2=8$ dan $g_{\mathrm{i}}=57, g_{\mathrm{i}}=57, g_{\mathrm{i}+1}=28$

yang memenuhi syarat adalah poim (e)

Jika, $\mathrm{r} \leq \mathrm{b}$ dan $\mathrm{m} \leq 2^{\mathrm{n}} / 2$ dan $\boldsymbol{g}_{\mathrm{i}} \geq \boldsymbol{g}_{\mathrm{i}+\mathbf{1}}$ 'maka

$\left.\left(g_{\mathrm{i}}{ }^{\prime}, g_{i+1}\right)^{\prime}\right)\left(g_{i+}\left[\frac{m}{2}\right], g_{i+1+}\left[\frac{m}{2}\right]\right)$

$\left(g \mathrm{i}^{\prime} g \mathrm{i}_{+1}\right)=\left(57+\left[\frac{3}{2}\right], 28+\left[\frac{3}{2}\right]\right)=(57+1,28+2)=(58,30)$

Langkah-langkah ekstraksi pesan

1. Hitunglah selisih 2 piksel bertetangga $\left(\boldsymbol{g}_{\mathbf{i}}, \boldsymbol{g}_{\boldsymbol{i}+\mathbf{1}}\right)$ $\mathrm{d}_{\mathrm{i}}=\left|g \mathrm{i}_{+1}-g \mathrm{i}\right|$

2. Tentukan batas bawah $\left(\mathbf{l}_{\mathbf{k}}\right)$ dan jumlah bit $\mathbf{n}$, dengan cara : $\mathrm{l}_{\mathrm{k}} \leq \mathrm{d}_{\mathrm{i}}<\mathrm{l}_{\mathrm{k}+1}$

3. Hitunglah nilai sisa hasil bagi (remainder) $\mathrm{b}=\left(g \mathrm{i}+g \mathrm{i}_{+1}\right) \bmod \mathbf{2}^{\prime}$

\section{ANALISA DAN PEMBAHASAN}

Penelitian ini menggunakan wadah penampung yang berupa gambar dan pesan akan disembunyikan ke dalam wadah penampung tersebut. Metode yang digunakan merupakan Modulus Function (MF), penerapan metode ini dilakukan dengan mengubah pesan yang akan disisipkan menjadi bentuk biner dan mengubah file gambar yang menjadi penampungnya ke bentuk biner dan kemudian diubah kebentuk desimal. Proses penyisipan bergantung dengan seberapa besar selisih antara desimal pada file gambar dan hasil dari selisih tersebut terus berlangsung hingga semua biner pesan tersisipkan pada desimalfile gambar. Hasil dari penyisipan biner pesan akan mengubah bentuk desimal dari file gambar.

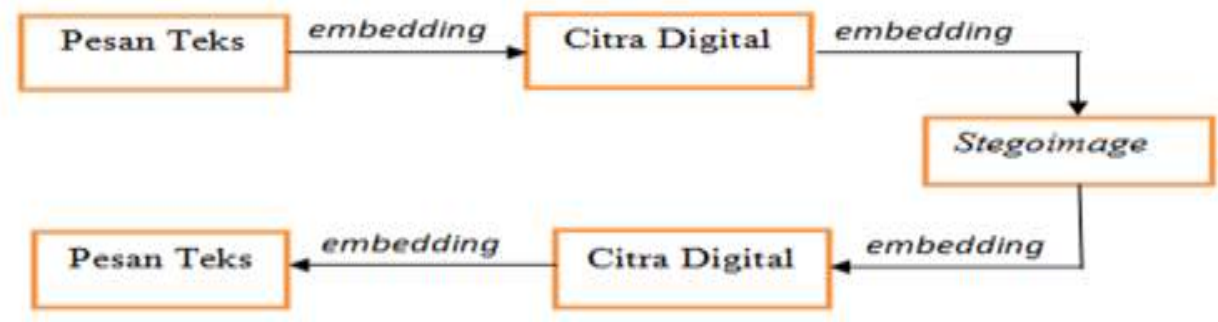

Gambar 1. Prosedur Penyisipan Dalam Gambar 
Penerapan metode Modulus Function (MF) pada file gambaruntuk mengamankan pesan dilakukan agar pengguna yang tidak memiliki hak tidak bisa membaca atau mengerti pesan tersebut . Penyisipan pesan dilakukan dengan mengubah pesan menjadi bentuk biner dan di sisipkan ke dalamfile gambardengan menggunakan metode Modulus Function (MF), sebelum dilakukan penyisipan maka file gambar harus dirubah menjadi bentuk desimal. File gambar yang digunakan adalah citragambar dengan berdimensi719 x 960 dan memiliki pixsel 10x10 yang memiliki nilai dari R 10x10, G 10X10, dan B 10x10.

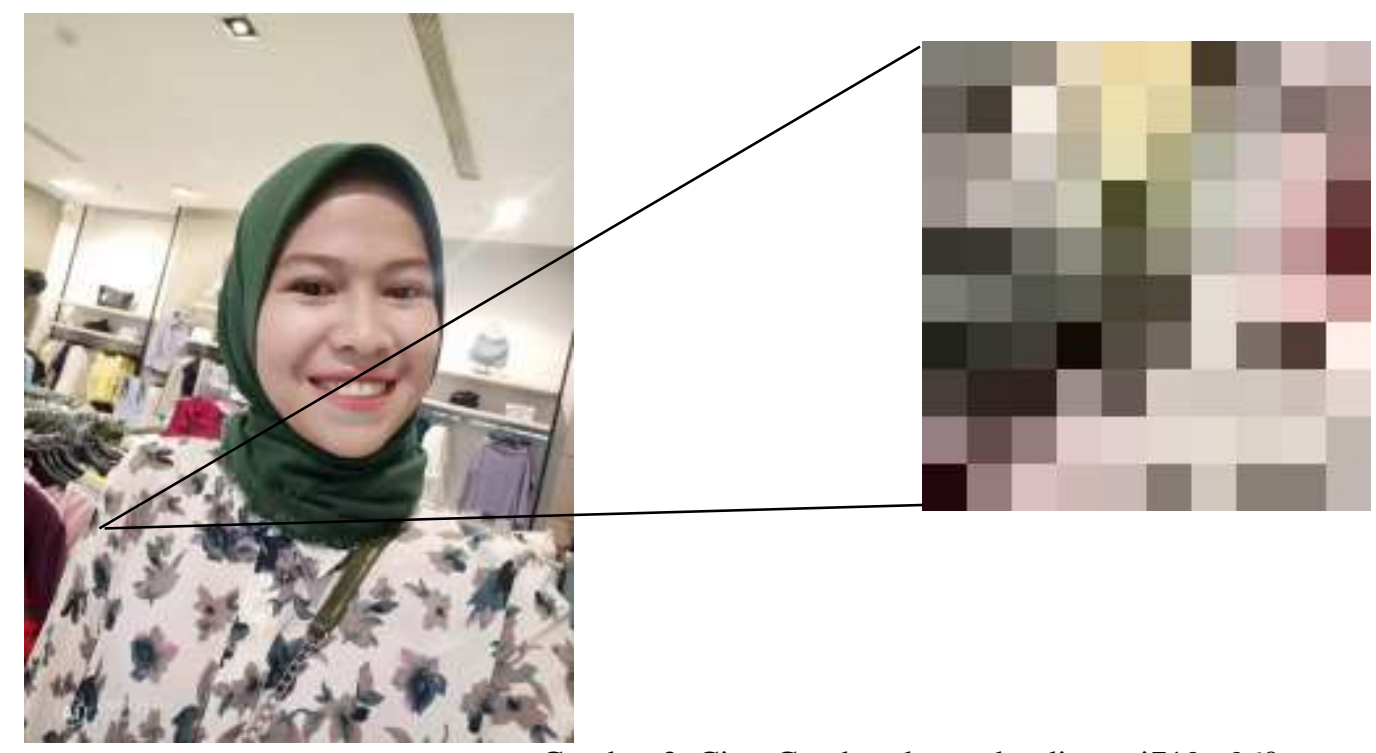

Gambar 2. Citra Gambar denganberdimensi719x 960

Berikut tampilan yang dijadikan sampel pengujian dengan menggunakan matlab:

Tabel 1. Citra Kanal R dengan Pixel $10 \times 10$

\begin{tabular}{llllllllll}
\hline 121 & 107 & 111 & 125 & 133 & 126 & 119 & 116 & 108 & 97 \\
135 & 122 & 117 & 122 & 130 & 135 & 134 & 120 & 99 & 86 \\
147 & 136 & 123 & 117 & 124 & 131 & 130 & 113 & 93 & 84 \\
135 & 134 & 123 & 121 & 123 & 120 & 114 & 105 & 95 & 91 \\
130 & 135 & 126 & 124 & 116 & 109 & 104 & 104 & 105 & 104 \\
125 & 133 & 123 & 117 & 107 & 99 & 97 & 105 & 113 & 112 \\
121 & 126 & 116 & 111 & 107 & 101 & 102 & 111 & 116 & 113 \\
110 & 114 & 111 & 114 & 107 & 111 & 111 & 117 & 120 & 117 \\
110 & 104 & 107 & 117 & 127 & 119 & 115 & 118 & 123 & 122 \\
108 & 108 & 108 & 118 & 132 & 127 & 121 & 120 & 122 & 120 \\
\hline
\end{tabular}

Tabel 2. Citra Kanal G dengan Pixel $10 \times 10$

\begin{tabular}{llllllllll}
\hline 144 & 143 & 133 & 131 & 134 & 132 & 126 & 117 & 106 & 102 \\
139 & 145 & 136 & 134 & 128 & 121 & 116 & 117 & 117 & 116 \\
135 & 143 & 133 & 127 & 119 & 111 & 110 & 118 & 125 & 124 \\
131 & 136 & 126 & 121 & 119 & 113 & 115 & 124 & 128 & 125 \\
120 & 124 & 121 & 124 & 128 & 122 & 123 & 130 & 132 & 129 \\
110 & 114 & 117 & 127 & 138 & 130 & 127 & 130 & 134 & 133 \\
118 & 118 & 118 & 128 & 142 & 137 & 132 & 132 & 133 & 131 \\
133 & 131 & 124 & 129 & 145 & 144 & 141 & 137 & 132 & 125 \\
142 & 136 & 139 & 134 & 141 & 144 & 147 & 140 & 133 & 133 \\
133 & 135 & 145 & 140 & 136 & 133 & 131 & 132 & 136 & 136 \\
\hline
\end{tabular}

\begin{tabular}{cccccccccc}
\multicolumn{4}{c}{ Tabel 3. Citra Kanal } & B dengan Pixel $10 \times 10$ \\
\hline 43 & 43 & 42 & 41 & 42 & 41 & 39 & 34 & 30 & 25 \\
42 & 46 & 50 & 47 & 48 & 45 & 42 & 37 & 32 & 30 \\
40 & 43 & 48 & 51 & 50 & 46 & 44 & 41 & 41 & 40 \\
39 & 33 & 39 & 45 & 45 & 47 & 51 & 50 & 50 & 45 \\
39 & 29 & 31 & 35 & 39 & 46 & 52 & 48 & 45 & 43
\end{tabular}




\begin{tabular}{llllllllll}
46 & 39 & 38 & 36 & 37 & 42 & 42 & 37 & 37 & 40 \\
52 & 53 & 50 & 42 & 35 & 37 & 36 & 35 & 39 & 41 \\
48 & 57 & 53 & 46 & 35 & 34 & 29 & 28 & 34 & 33 \\
44 & 53 & 52 & 45 & 36 & 31 & 25 & 27 & 34 & 28 \\
43 & 50 & 47 & 45 & 42 & 36 & 32 & 35 & 39 & 28 \\
\hline
\end{tabular}

Langkah-langkah Penyisipan Pesan kedalam Citra Digital

Pesan yang akan disisipkan adalah 'RAHIMA' yang akan dirubah menjadi bentuk biner.

1. Merubah pesan menjadi biner 8 bit dan File Gambarmenjadi desimal

Pesan

: RAHIMA

File Gambar : :CitraGambar dengan pixel720 x 963

Merubah bentuk pesan menjadi bine

Tabel 4. Biner Pesan

\begin{tabular}{ll}
\hline Karakter & Biner \\
\hline R & 01010010 \\
A & 01000001 \\
H & 01001000 \\
I & 01001001 \\
M & 01001101 \\
A & 01000001 \\
\hline
\end{tabular}

Sehingga biner dari pesan menjadi :

010100100100000101001000010010010100110101000001

Merubah File Gambar menjadi bentuk desimal dan mengambil sampel biner sebesar 10x10

Iterasi ke-1

Pesan"82" di ubah jadi biner 8 bit.

Pesan $=$ "01010010"

2. Proses Penyisipan Pesan Ke Dalam File Gambar

Mencari selisih 2 pixel bertetangga antar desimal File Gambar

\begin{tabular}{llllllllll}
121 & 107 & 111 & 125 & 133 & 126 & 119 & 116 & 108 & 97 \\
135 & 122 & 117 & 122 & 130 & 135 & 134 & 120 & 99 & 86 \\
147 & 136 & 123 & 117 & 124 & 131 & 130 & 113 & 93 & 84 \\
135 & 134 & 123 & 121 & 123 & 120 & 114 & 105 & 95 & 91 \\
130 & 135 & 126 & 124 & 116 & 109 & 104 & 104 & 105 & 104 \\
125 & 133 & 123 & 117 & 107 & 99 & 97 & 105 & 113 & 112 \\
121 & 126 & 116 & 111 & 107 & 101 & 102 & 111 & 116 & 113 \\
110 & 114 & 111 & 114 & 107 & 111 & 111 & 117 & 120 & 117 \\
110 & 104 & 107 & 117 & 127 & 119 & 115 & 118 & 123 & 122 \\
108 & 108 & 108 & 118 & 132 & 127 & 121 & 120 & 122 & 120 \\
\hline
\end{tabular}

$d_{i}=\left|\boldsymbol{g}_{i+1}-\boldsymbol{g}_{i}\right|$

$d_{i}=|107-121|=14$

3. Mencari Range

Untuk mencari rangemaka dibutuhkan tabel, tabel range digunakan untuk mengetahui rentang nilai dan jumlah bit dengan berdasarkan nilai yang telah didapat dari selisih nilai desimal $\left(\mathrm{d}_{\mathrm{i}}\right)$ dan dicocokan pada nilai batas bawah $\left(\mathrm{l}_{\mathrm{k}}\right)$ dan batas atas $\left(\mathrm{u}_{\mathrm{k}}\right)$ atau $\mathrm{l}_{\mathrm{k}} \leq \mathrm{d}_{\mathrm{i}} \leq \mathrm{u}_{\mathrm{k}}$

Tabel 5. Rentang Nilai

\begin{tabular}{llll}
\multicolumn{5}{c}{ Tabel 5. Rentang Nilai } \\
\hline Kuantisasi Ke-k & Batas Bawah - Batas Atas $\mathrm{L}_{\mathrm{k}}-\mathrm{U}_{\mathrm{k}}$ & Rentang Nilai & Jumlah Bit n \\
\hline 1 & $0-7$ & 8 & 3 \\
2 & $8-15$ & 8 & 3 \\
3 & $16-31$ & 16 & 4 \\
4 & $32-63$ & 32 & 5 \\
5 & $64-127$ & 64 & 6 \\
6 & $128-255$ & 128 & 7 \\
\hline $\mathrm{L}_{\mathrm{k}} \leq \mathrm{d}_{\mathrm{i}}<\mathrm{L}_{\mathrm{k}+1}$ & & & \\
$8 \leq \mathrm{d}_{\mathrm{i}}<15, \quad \mathrm{~L}_{\mathrm{k}}=8$, & $\mathrm{n}=3, \quad 2^{3}=8$ &
\end{tabular}

4. Mencari Lebar Dari Optimum Range

Untuk mencari lebar optimum diperlukan nilai rangeyaitu nilai batas bawah $\left(I_{k}\right)$

$\mathbf{b}=010=2$, sisa pesan $={ }^{'} 10010$ '

5. Menghitung nilai sisa hasil bagi (Remainder) 
Untuk mencari nilai Remainderyaitu hitung nilai hasil bagi kemudian dimodulus kan dengan nilai jumlah $2^{\text {n }}$

$\mathrm{r}=\left(\boldsymbol{g}_{\boldsymbol{i}}+\boldsymbol{g}_{\boldsymbol{i}+\mathbf{1}}\right) \bmod 2^{\mathrm{n}}$

$\mathrm{r}=(121+107) \bmod 8$

$\mathrm{r}=228 \bmod 8=4$

6. Hitung

$\mathrm{m}=|\mathrm{r}-\mathrm{b}|=$ dan $\mathrm{m}^{\prime}=\left|2^{\mathrm{n}}-\mathrm{m}\right|$

$\mathrm{m}=|4-2|=2$ dan

$\mathrm{m}^{\prime}=\left|2^{\mathrm{n}}-\mathrm{m}\right|=\left|2^{3}-2\right|=8-2=6$

7. Untuk menentukan nilai pixel baru atau nilai pixel bertetangga yaitudengan cara berikut :

a. Jika $\mathrm{r}>\mathrm{b}$ dan $\mathrm{m} \leq 2^{n} / 2$ dan $g_{1}-g_{i+1^{\prime}}$ maka

$$
\left(g_{\mathrm{i}}{ }^{\prime}, g_{i+1}\right)^{\prime}=\left(g_{i}-\left[\frac{m}{2}\right], g_{i+1}-\left[\frac{m}{2}\right]\right)
$$

b. Jika $\mathrm{r}>$ b dan $\mathrm{m} \leq 2^{n} / 2$ dan $g_{1}-g_{i+1^{\prime}}$ maka $\left(g_{\mathrm{i}}, g_{i+1}{ }^{\prime}\right)=\left(g_{i}-\left[\frac{m}{2}\right], g_{i+1}-\left[\frac{m}{2}\right]\right)$

c. Jika $\mathrm{r}>\mathrm{b}$ dan $\mathrm{m} \leq 2^{n} / 2$ dan $g_{1}-g_{i+1^{\prime}}$ maka $\left(g_{\mathrm{i}}{ }^{\prime}, g_{i+1}\right)^{\prime}=\left(g_{i}-\left[\frac{m}{2}\right], g_{i+1}+\left[\frac{m}{2}\right]\right)$

d. Jika $\mathrm{r}>\mathrm{b}$ dan $\mathrm{m} \leq 2^{n} / 2$ dan $g_{1}-g_{i+1^{\prime}}$ maka $\left(g_{\mathrm{i}}, g_{i+1}{ }^{\prime}\right)=\left(g_{i}-\left[\frac{m}{2}\right], g_{i+1}+\left[\frac{m}{2}\right]\right)$

e. Jika $\mathrm{r}>\mathrm{b}$ dan $\mathrm{m} \leq 2^{n} / 2$ dan $g_{1}-g_{i+1^{\prime}}$ maka $\left(g_{\mathrm{i}}, g_{i+1}{ }^{\prime}\right)=\left(g_{i}-\left[\frac{m}{2}\right], g_{i+1}+\left[\frac{m}{2}\right]\right)$

f. Jika $\mathrm{r}>$ b dan $\mathrm{m} \leq 2^{n} / 2$ dan $g_{1}-g_{i+1^{\prime}}$ maka $\left(g_{\mathrm{i}}, g_{i+1}{ }^{\prime}\right)=\left(g_{i}-\left[\frac{m}{2}\right], g_{i+1}+\left[\frac{m}{2}\right]\right)$

g. Jika $\mathrm{r}>\mathrm{b}$ dan $\mathrm{m} \leq 2^{n} / 2$ dan $g_{1}-g_{i+1^{\prime}}$ maka $\left(g_{\mathrm{i}}, g_{i+1}\right)^{\prime}=\left(g_{i}-\left[\frac{m}{2}\right], g_{i+1}-\left[\frac{m}{2}\right]\right)$

h. Jika $\mathrm{r}>\mathrm{b}$ dan $\mathrm{m} \leq 2^{n} / 2$ dan $g_{1}-g_{i+1^{\prime}}$ maka $\left(g_{\mathrm{i}}{ }^{\prime}, g_{i+1}{ }^{\prime}\right)=\left(g_{i}-\left[\frac{m}{2}\right], g_{i+1}-\left[\frac{m}{2}\right]\right)$

Yang memenuhi syarat adalah poin (A)

Jika, $\mathrm{r} \leq \mathrm{b}$ dan $\mathrm{m}>2^{\mathrm{n}} / 2$ dan $\boldsymbol{g}_{\boldsymbol{i}} \geq \boldsymbol{g}_{\boldsymbol{i}+\mathbf{1}}$, maka

$\left(\boldsymbol{g}_{\boldsymbol{i}}, \boldsymbol{g}_{\boldsymbol{i}+\boldsymbol{1}}{ }^{\prime}\right)=\left(\boldsymbol{g}_{\boldsymbol{i}}-\left[\frac{m}{2}\right], \boldsymbol{g}_{\boldsymbol{i}+\mathbf{1}}-\left[\frac{m}{2}\right]\right)$

$\left(\boldsymbol{g}_{\boldsymbol{i}}, \boldsymbol{g}_{\boldsymbol{i}+1}\right)=\left(121-\left[\frac{2}{2}\right], 107-\left[\frac{2}{2}\right]\right)$ $=(121-1,107-1)=(120,106)$

Tabel 6. Pesan Iterasi 1

\begin{tabular}{llllllllll}
\hline 121 & 107 & 111 & 125 & 133 & 126 & 119 & 116 & 108 & 97 \\
135 & 122 & 117 & 122 & 130 & 135 & 134 & 120 & 99 & 86 \\
147 & 136 & 123 & 117 & 124 & 131 & 130 & 113 & 93 & 84 \\
135 & 134 & 123 & 121 & 123 & 120 & 114 & 105 & 95 & 91 \\
130 & 135 & 126 & 124 & 116 & 109 & 104 & 104 & 105 & 104 \\
125 & 133 & 123 & 117 & 107 & 99 & 97 & 105 & 113 & 112 \\
121 & 126 & 116 & 111 & 107 & 101 & 102 & 111 & 116 & 113 \\
110 & 114 & 111 & 114 & 107 & 111 & 111 & 117 & 120 & 117 \\
110 & 104 & 107 & 117 & 127 & 119 & 115 & 118 & 123 & 122 \\
108 & 108 & 108 & 118 & 132 & 127 & 121 & 120 & 122 & 120 \\
\hline
\end{tabular}

Tabel 7. Hasil Perhitungan Penyisipan Pesan Iterasi 1

\begin{tabular}{llllllllll}
\hline 120 & 106 & 111 & 125 & 133 & 126 & 119 & 116 & 108 & 97 \\
135 & 122 & 117 & 122 & 130 & 135 & 134 & 120 & 99 & 86 \\
147 & 136 & 123 & 117 & 124 & 131 & 130 & 113 & 93 & 84 \\
135 & 134 & 123 & 121 & 123 & 120 & 114 & 105 & 95 & 91 \\
130 & 135 & 126 & 124 & 116 & 109 & 104 & 104 & 105 & 104 \\
125 & 133 & 123 & 117 & 107 & 99 & 97 & 105 & 113 & 112 \\
121 & 126 & 116 & 111 & 107 & 101 & 102 & 111 & 116 & 113 \\
110 & 114 & 111 & 114 & 107 & 111 & 111 & 117 & 120 & 117 \\
110 & 104 & 107 & 117 & 127 & 119 & 115 & 118 & 123 & 122 \\
108 & 108 & 108 & 118 & 132 & 127 & 121 & 120 & 122 & 120 \\
\hline
\end{tabular}


Iterasi ke-5

1. $00010100=20$

2. $\mathrm{d}_{\mathrm{i}}=\left|\boldsymbol{g}_{\boldsymbol{i}+\mathbf{1}}-\boldsymbol{g}_{\boldsymbol{i}}\right|=|97-108|=11$

3. $\mathrm{L}_{\mathrm{k}} \leq \mathrm{d}_{\mathrm{i}}<\mathrm{L}_{\mathrm{k}+1}$

$8 \leq \mathrm{d}_{\mathrm{i}}<15, \quad \mathrm{~L}_{\mathrm{k}}=8, \quad \mathrm{n}=3, \quad 2^{3}=8$

4. $\mathbf{b}=000=0$, sisa pesan $={ }^{\prime} 10100$ '

5. $\mathrm{r}=\left(\boldsymbol{g}_{\boldsymbol{i}}+\boldsymbol{g}_{\boldsymbol{i}+\mathbf{1}}\right) \bmod 2^{\mathrm{n}}$

$\mathrm{r}=(108+97) \bmod 8$

$\mathrm{r}=205 \bmod 8=5$

6. $m=|r-b|=|5-0|=5$ dan

$$
\mathrm{m}^{\prime}=\left|2^{\mathrm{n}}-\mathrm{m}\right|=\left|2^{3}-5\right|=8-5=3
$$

7. $\mathrm{r}=5, \mathbf{b}=0, \mathrm{~m}=5, \mathrm{l}_{\mathrm{k}} / 2=4$ dan $\boldsymbol{g}_{\boldsymbol{i}}=108, \boldsymbol{g}_{\boldsymbol{i}+\mathbf{1}}=97$

Yang memenuhi syarat adalah poin (A)

Jika, $\mathrm{r} \leq \mathrm{b}$ dan $\mathrm{m}>2^{\mathrm{n}} / 2$ dan $\boldsymbol{g}_{\boldsymbol{i}} \geq \boldsymbol{g}_{\boldsymbol{i}+\mathbf{1}}$, maka

$\left(\boldsymbol{g}_{i}\right.$

$$
\begin{aligned}
\left.\boldsymbol{g}_{\boldsymbol{i}+\mathbf{1}}\right)=\left(\boldsymbol{g}_{\boldsymbol{i}}-\left[\frac{m}{2}\right], \boldsymbol{g}_{\boldsymbol{i}+\mathbf{1}}-\left[\frac{m}{2}\right]\right) \\
\left(\boldsymbol{g}_{\boldsymbol{i}}, \boldsymbol{g}_{\boldsymbol{i + 1}}\right)=\left(108-\left[\frac{5}{2}\right], 97-\left[\frac{5}{2}\right]\right) \\
=(108-2,97-3)=(106,94)
\end{aligned}
$$

Tabel 8. Pesan Iterasi 5

\begin{tabular}{llllllllll}
\hline 121 & 107 & 111 & 125 & 133 & 126 & 119 & 116 & 108 & 97 \\
135 & 122 & 117 & 122 & 130 & 135 & 134 & 120 & 99 & 86 \\
147 & 136 & 123 & 117 & 124 & 131 & 130 & 113 & 93 & 84 \\
135 & 134 & 123 & 121 & 123 & 120 & 114 & 105 & 95 & 91 \\
130 & 135 & 126 & 124 & 116 & 109 & 104 & 104 & 105 & 104 \\
125 & 133 & 123 & 117 & 107 & 99 & 97 & 105 & 113 & 112 \\
121 & 126 & 116 & 111 & 107 & 101 & 102 & 111 & 116 & 113 \\
110 & 114 & 111 & 114 & 107 & 111 & 111 & 117 & 120 & 117 \\
110 & 104 & 107 & 117 & 127 & 119 & 115 & 118 & 123 & 122 \\
108 & 108 & 108 & 118 & 132 & 127 & 121 & 120 & 122 & 120 \\
\hline
\end{tabular}

Tabel 9. Hasil Perhitungan Penyisipan Pesan Iterasi 5

\begin{tabular}{llllllllll}
\hline 120 & 106 & 111 & 125 & 133 & 126 & 119 & 117 & 106 & 94 \\
135 & 122 & 117 & 122 & 130 & 135 & 134 & 120 & 99 & 86 \\
147 & 136 & 123 & 117 & 124 & 131 & 130 & 113 & 93 & 84 \\
135 & 134 & 123 & 121 & 123 & 120 & 114 & 105 & 95 & 91 \\
130 & 135 & 126 & 124 & 116 & 109 & 104 & 104 & 105 & 104 \\
125 & 133 & 123 & 117 & 107 & 99 & 97 & 105 & 113 & 112 \\
121 & 126 & 116 & 111 & 107 & 101 & 102 & 111 & 116 & 113 \\
110 & 114 & 111 & 114 & 107 & 111 & 111 & 117 & 120 & 117 \\
110 & 104 & 107 & 117 & 127 & 119 & 115 & 118 & 123 & 122 \\
108 & 108 & 108 & 118 & 132 & 127 & 121 & 120 & 122 & 120 \\
\hline
\end{tabular}

Setelah mendapatkan semua biner pesan yang telah disisipkan makamerubah bentuk biner tersebut dirubah kebentuk karakter agar mendapatkan pesan yang sesungguhnya.

Tabel 10. Biner Pesan

\begin{tabular}{ll}
\hline Biner & Karakter \\
\hline 01010010 & $\mathrm{R}$ \\
01000001 & $\mathrm{~A}$ \\
01001000 & $\mathrm{H}$ \\
01001001 & $\mathrm{I}$ \\
01001101 & $\mathrm{M}$ \\
01000001 & $\mathrm{~A}$ \\
\hline
\end{tabular}

Berdasarkan metode Modulus Function (MF) berhasil kembali merubah pesanyang telah disisipkan . 


\section{IMPLEMENTASI}

1. Membaca citra digital

Perintah membaca citra digital pada matlab adalah menggunakan perintah imread kemudian diikuti oleh lokasi penyisipan dari citra tersebut.

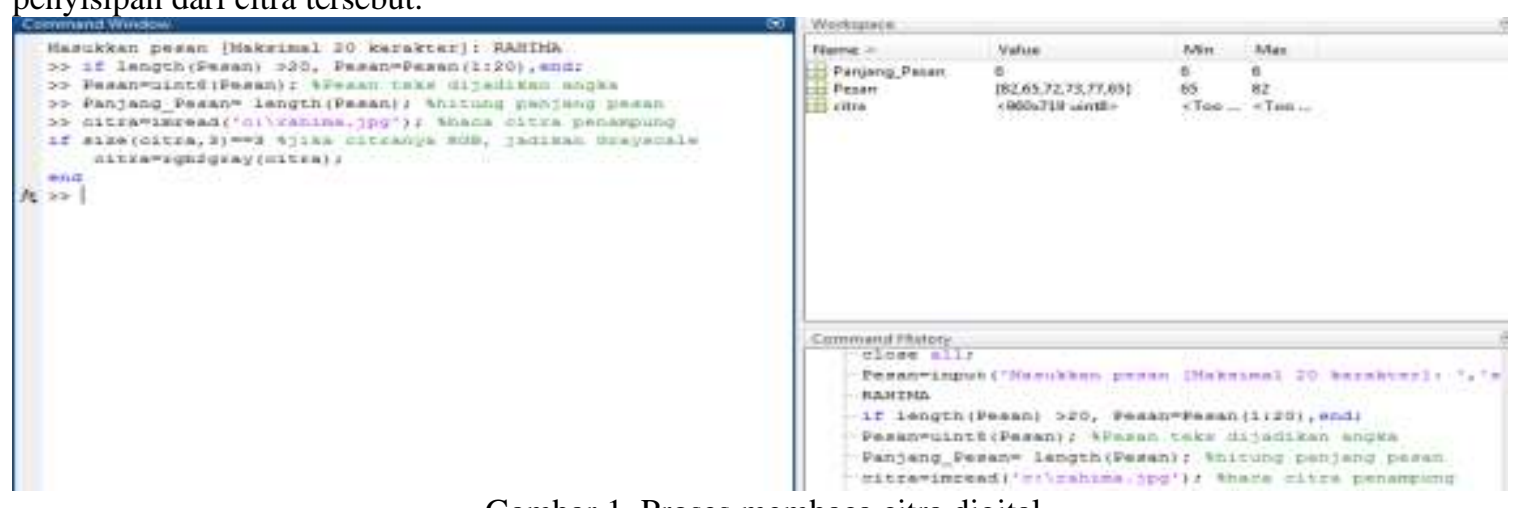

2. Menyisipkan pesan

Gambar 1. Proses membaca citra digital

Unutuk menyisipkan pesan ke dalam citra digital dilakukan dengan menggunakan metode Modulus Function. Sebelum melakukan penyisipan pesan dilakukan proses merubah matriks pesan menjadi vektor dan matriks citra penampung menjad

i vektor.

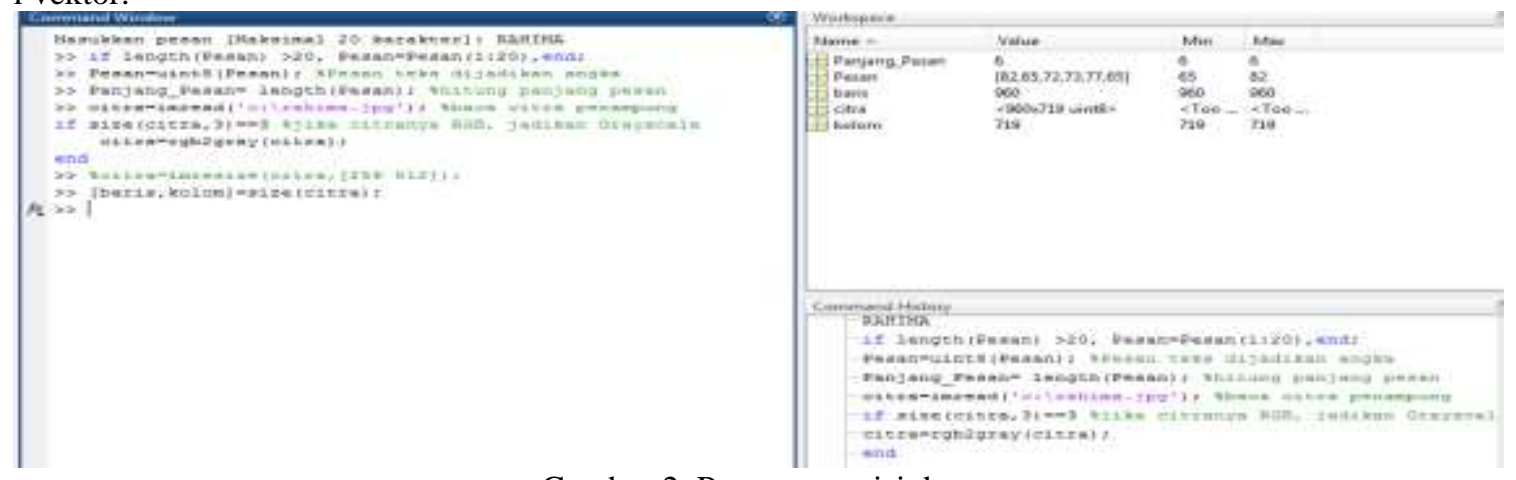

Gambar 2. Proses menyisipkan pesan

3. Menyisipkan stegoimage

Setelah pesan disisipkan ke dalam citra maka langkah selanjutnya adalah menyisipkan citra tersebut kedalam media penyimpanan dengan perintah imwrite diikuti oleh lokasi penyimpanan dan nama filenya.

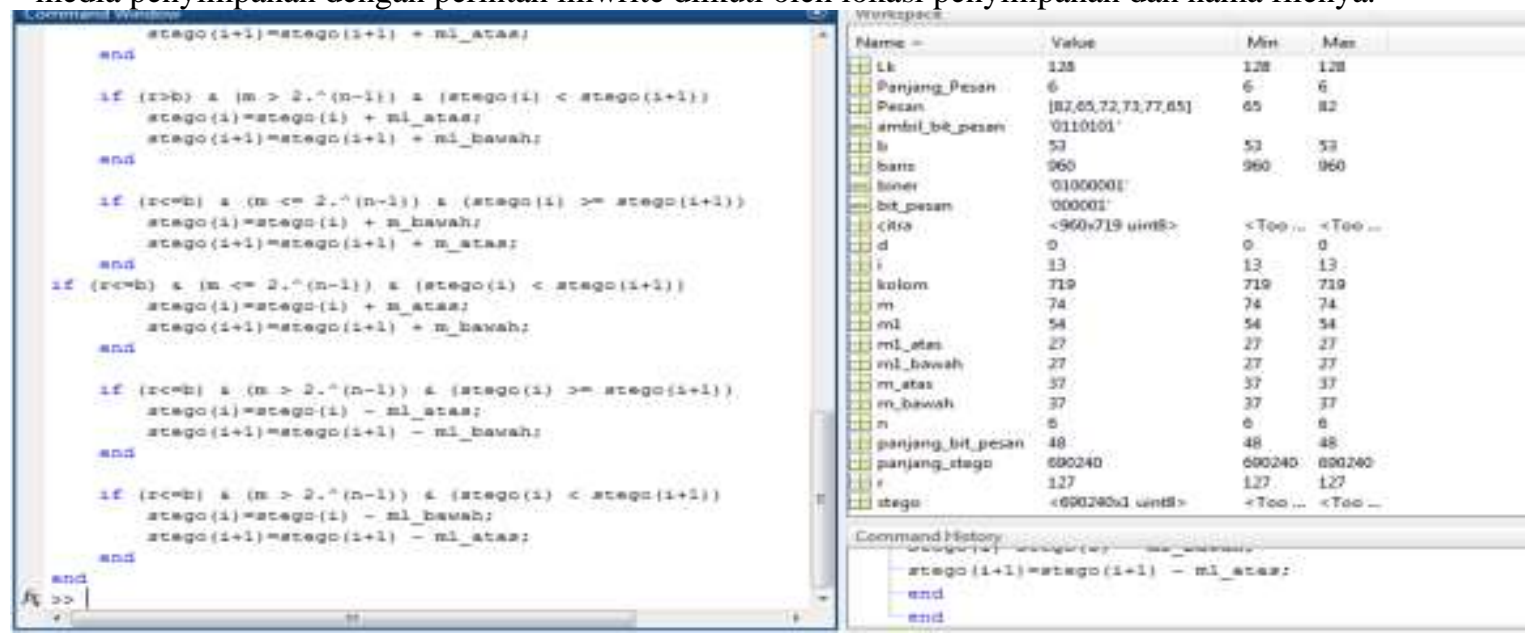

Langkah-langkah ekstraksi pesan :

Gambar 3. Proses menyisipkan stegoimage

1. Membaca Stegoimage

Untuk melakukan proses ekstraksi maka langkah pertama adalah membaca stegoimage dengan perintah imread diikuti oleh lokasi penyimpanan stego image. 


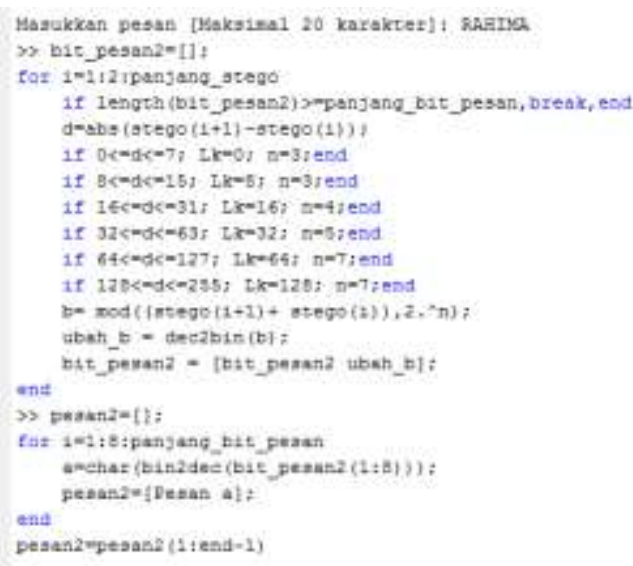

\begin{tabular}{|c|c|c|c|}
\hline Name - & Value & $\mathrm{Mn}$ & Mas \\
\hline ambil_tit pessan & จ110101 & & \\
\hline 思 & 127 & 127 & $12 \pi$ \\
\hline Etant & 960 & 900 & 960 \\
\hline \pm tiner & twaxcoos: & & \\
\hline ait beusn & 600001 & & \\
\hline - bitspesen? & 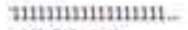 & & \\
\hline Qctos & estouch19 untes & $<100 \mathrm{~L}$ & $<100$ \\
\hline 里 & 0 & 0 & 0 \\
\hline$\boxplus_{i}$ & a & 61 & a \\
\hline Enolom. & 719 & 719 & 71 \\
\hline 䎅m & 74 & 74 & 74 \\
\hline 世ma & 54 & 54 & 54 \\
\hline 吾mi_mai & 27 & 27 & 27 \\
\hline 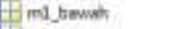 & $z$ & 27 & $n$ \\
\hline Hinjas & 37 & 37 & 3) \\
\hline Mn bawat: & 37 & 37 & 37 \\
\hline$\Theta_{n}$ & 7 & 7 & 7 \\
\hline Traryang_kit_pesan & 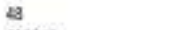 & 48 & 49 \\
\hline Qperjing_steps & 690005 & 690200 & 690045 \\
\hline fiesan & 'RAHAMA' & & \\
\hline 田 & 127 & $17 \pi$ & $12 \pi$ \\
\hline 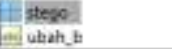 & 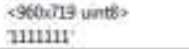 & $<100 \mathrm{H}$ & $\$ 100$ \\
\hline
\end{tabular}

Gambar 4. Membaca stegoimage

2. Ekstraksi pesan

Untuk melakukan proses ekstraksi pesan langkah pertama adalah membaca ekstraksi pesan dengan perintah imread diikuti oleh lokasi penyimpanan ekstraksi pesan.
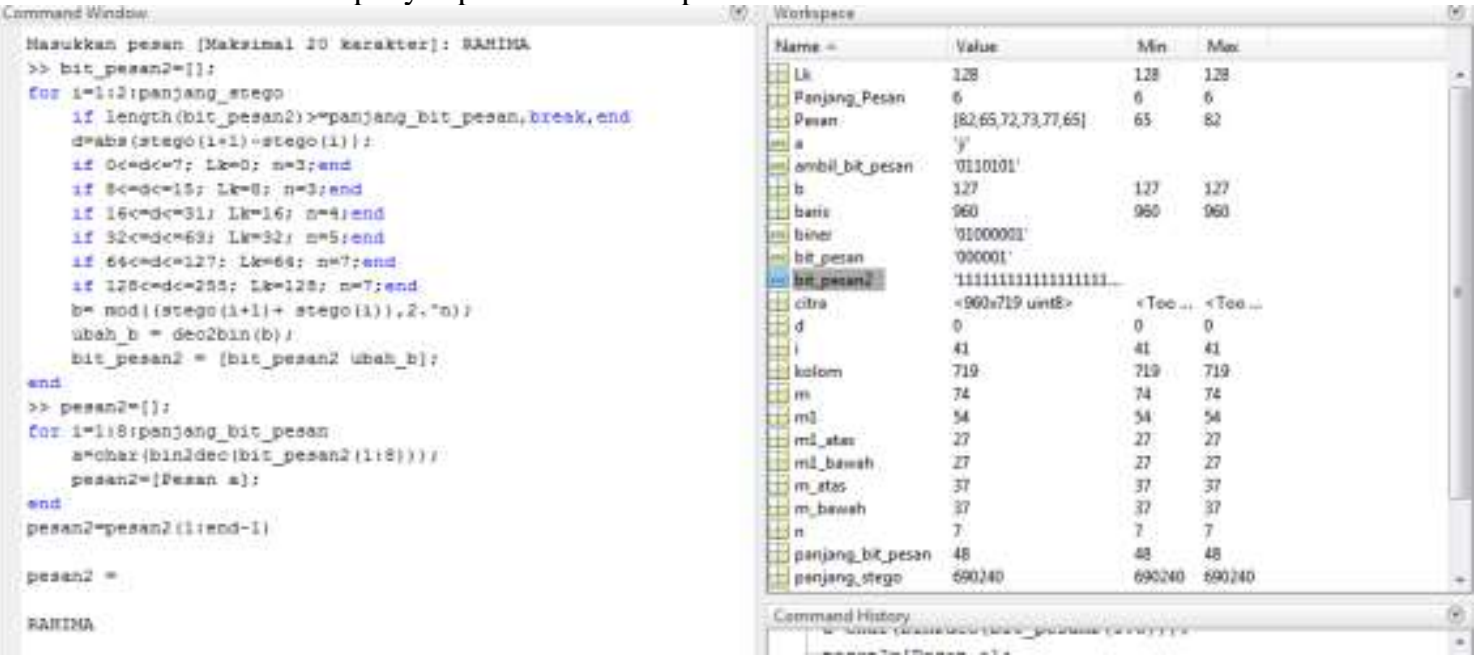

3. Menyimpan pesan

Gambar 5. Ekstraksi pesan

Untuk melakukan proses penyimpanan pesan langkah pertama adalah menyimpan pesan dengan perintah imread diikuti oleh lokasi penyimpanan pesan.

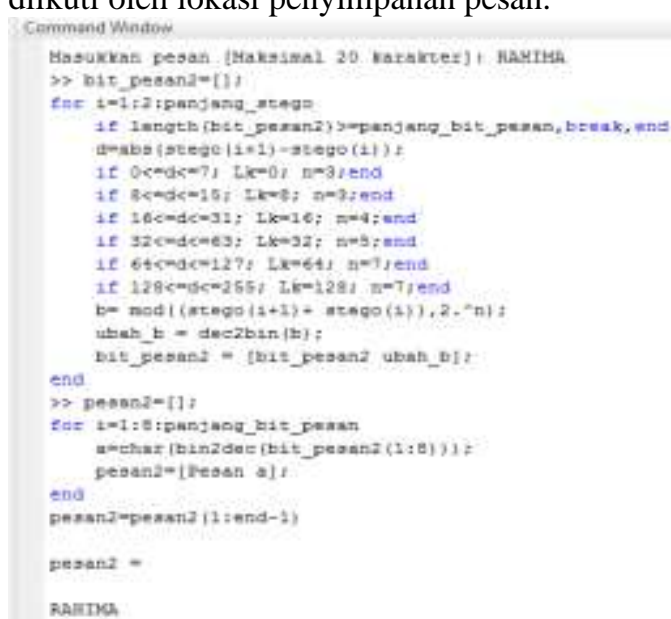

Gamabr 6. Menyimpan pesan

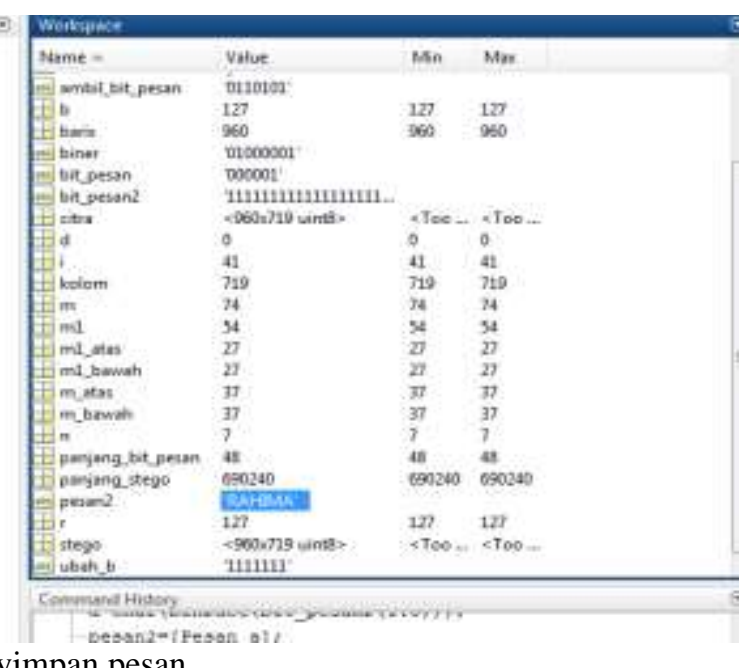

Tabel 4.1 Hasil Pengujian

File Asli citra




\begin{tabular}{|c|c|c|c|c|}
\hline & & & $\begin{array}{l}\text { Pesan } \\
\text { Input }\end{array}$ & $\begin{array}{l}\text { Pesan } \\
\text { Output }\end{array}$ \\
\hline 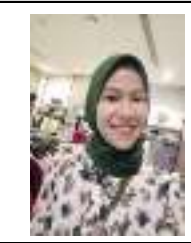 & yos & 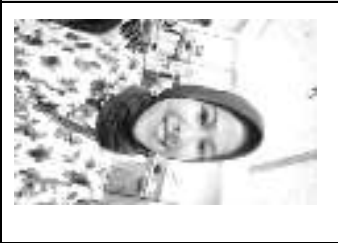 & $\begin{array}{l}\mathrm{R} \\
\mathrm{A} \\
\mathrm{H} \\
\mathrm{I} \\
\mathrm{M} \\
\mathrm{A}\end{array}$ & $\begin{array}{l}\text { Pesan } \\
\text { kembali }\end{array}$ \\
\hline 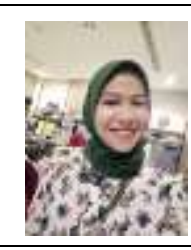 & 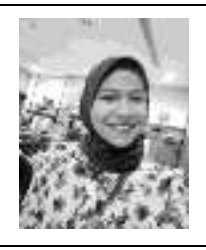 & 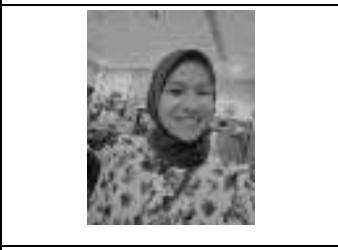 & $\begin{array}{l}\mathrm{R} \\
\mathrm{A} \\
\mathrm{H} \\
\mathrm{I} \\
\mathrm{M} \\
\mathrm{A}\end{array}$ & $\begin{array}{l}\text { Pesan } \\
\text { kembali }\end{array}$ \\
\hline $\sin _{x \rightarrow 2}$ & bes & $\left.y^{2}\right)^{2}$ & $\begin{array}{l}\mathrm{R} \\
\mathrm{A} \\
\mathrm{H} \\
\mathrm{I} \\
\mathrm{M} \\
\mathrm{A}\end{array}$ & $\begin{array}{l}\text { Pesan } \\
\text { kembali }\end{array}$ \\
\hline 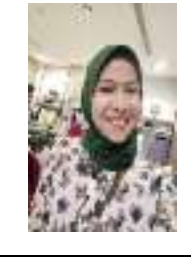 & 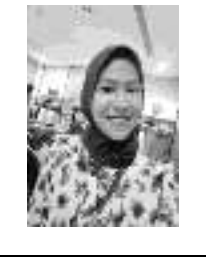 & Bes & $\begin{array}{l}\mathrm{R} \\
\mathrm{A} \\
\mathrm{H} \\
\mathrm{I} \\
\mathrm{M} \\
\mathrm{A}\end{array}$ & $\begin{array}{l}\text { Pesan } \\
\text { kembali }\end{array}$ \\
\hline
\end{tabular}

\section{Kesimpulan}

Berdasarkan hasil analisa penulis, dapat menyimpulkan secara garis besar dalam pembuatan sistem ini adalah sebagai berikut.

1. Proses penyisipan pesan teks pada citra digital dengan menggunakan Matlab.

2. Metode Modulus Function (MF)berhasil diterapkan untuk menyisipkan pesan teks pada citra digital.

3. Perubahan yang terjadi pada citra digital yang telah disispkan pesan teks tidak terlalu signifikan, sehingga tidak menimbulkan kecurigaan.

\section{REFERENCES}

[1] P. N. Andono, Pengolahan Citra Digital, Yogyakarta: Andi, 2017.

[2] 2. A. P. N. 1.Dita Angelia Suwiryo, "ANALISIS PERFORMA METODE IHWT (INTEGER HAAR WAVELET TRANSFORM) DAN MODULUS FUNCTION DENGAN METODE IHWT (INTEGER HAAR WAVELET TRANSFORM) DAN PVD (PIXEL VALUE DIFFERENCING) PADA KUALITAS CITRA DIGITAL”.

[3] A. Purwasito, “ANALISIS PESAN,” THE MESSENGER, Volume 9, Nomor 1, 2017.

[4] T. M. Pulung Nurtantio Andono, PENGOLAHAN CITRA DIGITAL, Yogyakarta: Andi, 2017. 